
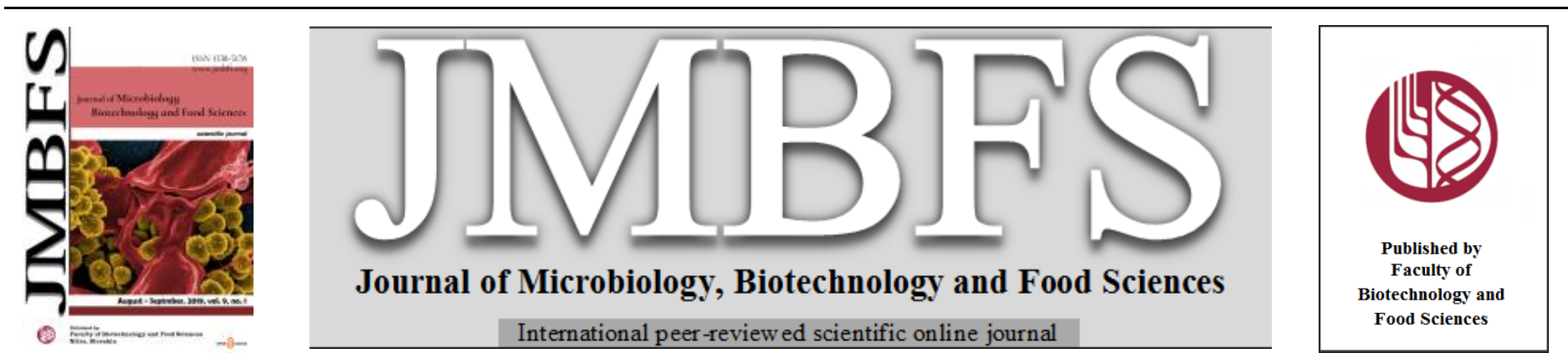

\title{
ROLE OF YEAST CONSORTIUM FOR THE REMEDIATION OF PERYLENE FROM AQUEOUS ENVIRONMENT: PROCESS OPTIMIZATION
}

\author{
Sanjeeb Kumar Mandal ${ }^{1}$, Nupur Ojha ${ }^{2}$ and Nilanjana Das $*^{3}$

\begin{abstract}
$\operatorname{Address}(e s)$ :
1,2,3Bioremediation Laboratory, School of Bio Sciences and Technology, VIT (Vellore Institute of Technology), Vellore-632014, Tamil Nadu, India. Tel.: +91 416 2202478; Fax: +914162243092.
\end{abstract}

*Corresponding author: nilanjanamitra@ vit.ac.in

doi: $10.15414 / j m b f s .2019 .9 .1 .132-139$

\section{ARTICLE INFO}

Received 26.11.2018

Revised 11.1.2019

Accepted 21. 5. 2019

Published 1. 8. 2019

Regular article

OPEN $\partial_{\text {ACCESS }}$

\begin{abstract}
Perylene (PRL), a five- ring nuclear polycyclic aromatic hydrocarbon (PAH) has attracted attention because of its toxic properties. This study aimed to evaluate the efficiency of yeast consortium $\mathrm{YC} 02$ to remediate PRL in presence of $\mathrm{ZnO}$ nanoparticles and produced biosurfactant in the growth medium. Response surface methodology (RSM), 3- level five variables Box-Behnken design (BBD) was employed to optimize the factors viz. $\mathrm{pH} 7.0$, temperature $30^{\circ} \mathrm{C}$, shaking speed $130 \mathrm{rpm}$, inoculum dosage $3 \%$ and zinc oxide nanoparticles $(\mathrm{ZnO})$ concentration $2 \mathrm{~g} \mathrm{~L}^{-1}$ after a period of 6 days of incubation for the enhanced degradation of PRL $(74 \pm 0.01 \%)$ using yeast consortium. It was well in close agreement with the predicated value obtained by RSM model yield ( $74 \pm 0.8 \%)$. Analysis of variance (ANOVA) showed F-value of $58.13, \mathrm{R}^{2}$ of 0.9790 , probability of $<0.0001$ and coefficient of variation of $1.32 \%$ confirmed the validity of the model. Degradation of PRL was assessed using GC-MS and FTIR analysis. Kinetic study demonstrated that PRL degradation fitted first order kinetic model. To the best of our knowledge, this is the first report on process optimization towards nanobioremediation of PRL using yeast consortium in presence of $\mathrm{ZnO}$ nanoparticles and produced biosurfactant in medium.
\end{abstract}

Keywords: Biosurfactant; nanobioremediation; PRL; polycyclic aromatic hydrocarbons (PAHs); response surface methodology (RSM); yeast consortium; $\mathrm{ZnO}$ nanoparticles

\section{INTRODUCTION}

Perylene (PRL) $\left(\mathrm{C}_{10} \mathrm{H}_{12}\right)$, as a representative of polycyclic aromatic hydrocarbons (PAHs) has been reported as hazardous pollutant (Donaldson et al., 1953). It is an extensively determined 5-ring $\mathrm{PAH}$, derives from varied sediment environments such as marine sediments (Slater et al., 2013), fresh water and river sediments and peats (Hu et al., 2014). PRL has been identified in marine and terrestrial sediments ad well as in brown coals, crude oils and sedimentary rocks (Marynowski $\boldsymbol{e t}$ al., 2015). The occurrence of PRL is mainly associated with the terrestrial organic matter (Stefanova et al., 2013). The terrestrial soil holds the precursors of PRL which are being transported by rivers to the coasts (Varnosfaderany et at., 2014). Although PRL has been the object of several environmental studies, report is very less on its toxicity. Respiratory tract lesions including tumors in respiratory tract have been reported as toxic effects of PRL (Kephalopoulos et al., 2014). The carcinogenic effects of PRL in human and animals exposed orally or by inhalation have also been reported (US EPA, 2007). The coke oven workers were found to be affected by high concentration of PRL which reduced their levels of serum immunoglobins (Irwin et al., 1997). Cunha et al. (2006) reported the toxicity of PRL on benthic bacteria and macro-fauna. The predominance of PRL over other PAHs has been found in marine sediments throughout the world at concentrations that are different from those of other PAHs (Itoh and Hanari, 2010).

There are many physico-chemical methods for remediation of PAHs which include chemical oxidation, photolysis, incineration, landfilling, volatilization and adsorption. But applications of these methods are limited due to certain drawbacks such as high operating cost, formation of toxic products etc. (Gan $\boldsymbol{e t}$ al., 2009). Microbial remediation is one of the most significant natural processes that can influence the fate of pollutants in both aquatic and terrestrial environment. Biodegradation is a promising method to remediate PAHs as it is inexpensive, environmental friendly and able to convert toxic substances into harmless products compared to conventional methods that need high cost and may produce hazardous by-products which can affect the environment (Qin $\boldsymbol{e t}$ al., 2017).

Biosurfactants have become one of the most versatile chemicals appropriate to be used for various industrial and environmental purposes. There are reports on bacteria and yeasts producing biosurfactants which are having lot of applications in various fields including remediation of number of pollutants(Raza $\boldsymbol{e t}$ al., 2007).

Recently, nanoparticles have been used as reductants or catalysts to improve various reactions due to their high surface areas and other characteristics (Nezahat et al., 2009). In addition, effect of nanoparticles on microorganisms has additionally created great interests. Nanoparticles are able to assist microbial activities (Shin and Cha, 2008). But extremely limited studies have been conducted on bioremediation of pollutants in presence of nanoparticles and produced biosurfactants in the growth medium using microbes (El-Sheshtawy and Ahmed, 2017)

Remediation of PRL through biological method is receiving attention now-adays. There are relatively few publications on successful microbial remediation of PRL (Hesham et al., 2006; Silva et al., 2009; Mandal and Das, 2018) . In addition, the use of microbial consortia is considered to be more stable and effective than using single organism because of their diversity and synergistic effect of metabolic activity that occur in microbial consortia (Hesham et al., 2006; Mishra et al., 2014; Mandal and Das, 2018). So far, no report is available on nanobioremediation of PRL in the presence of nanoparticles and produced biosurfactant in the medium using microbial consortium.

In the present study, an attempt has been made to optimize the remediation process using essential variables that enhance the biodegradability of PRL using 3-level Box- Behnken design which can provide a mathematical model showing the influence of each variable and their interactions. Experiments were conducted to study the biodegradation of PRL using yeast consortium in presence of $\mathrm{ZnO}$ nanoparticles and produced biosurfactant in the growth medium. To the best of our knowledge, this is the first study in which process optimization has been done towards nanobioremediation of PRL using yeast consortium in presence of $\mathrm{ZnO}$ nanoparticles and produced biosurfactant in medium.

\section{MATERIALS AND METHODS}

\section{Microorganism}

In our previous study, the yeast consortium $\mathrm{YC} 02$ was already reported as potential degrader of PRL (Mandal and Das, 2018) which consist of three yeast 
isolates viz. Hanseniaspora opuntiae NS02, Debaryomyces hansenii $\mathrm{NS} 03$ and Hanseniaspora valbyensis NS04. So, YC02 was selected for the present study.

\section{Synthesis and characterization of $\mathrm{ZnO}$ nanoparticles}

The synthesis of $\mathrm{ZnO}$ nanoparticles was done following the standard method (Litt and Almquist, 2009). The $\mathrm{ZnO}$ nanoparticles were prepared by the precipitation technique using zinc chloride $\left[\mathrm{ZnCl}_{2} \cdot 9 \mathrm{H}_{2} \mathrm{O}\right]$ (Sigma-Aldrich). In practical, $2.6 \mathrm{~g}$ of $\mathrm{ZnCl}_{2}$ was dissolved in $1000 \mathrm{ml}$ distilled water and precipitated using 33\% dilute aqueous ammonium hydroxide solution (Sigma-Aldrich) at room temperature until the $\mathrm{pH}$ reached a value of 13 . The slurry was then agitated for $30 \mathrm{~min}$. The resultant precipitates were filtered and washed carefully, and the sample was dried at $100^{\circ} \mathrm{C}$ for $12 \mathrm{~h}$. The characterization of $\mathrm{ZnO}$ nanoparticles was done using UV spectroscopy, X ray diffraction (XRD), Fourier transform Infrared spectroscopy (FTIR) analysis, TEM and EDX analysis.

\section{Production of biosurfactant in culture media}

For biosurfactant production, a mineral salt medium (MSM) was prepared. Trace element solution containing $\left(\mathrm{g} \mathrm{L}^{-1}\right)$ : 0.116 of $\mathrm{FeSO}_{4} .7 \mathrm{H}_{2} \mathrm{O}, 0.232$ of $\mathrm{H}_{3} \mathrm{BO}_{3}, 0.41$ of $\mathrm{CoCl}_{2} .6 \mathrm{H}_{2} \mathrm{O}, 0.008$ of $\mathrm{CuSO}_{4} .5 \mathrm{H}_{2} \mathrm{O}, 0.008$ of $\mathrm{MnSO}_{4} . \mathrm{H}_{2} \mathrm{O}, 0.02$ of $\left(\mathrm{NH}_{4}\right)_{6} \mathrm{Mo}_{7} \mathrm{O}_{24}$ and 0.174 of $\mathrm{ZnSO}_{4}$ were added to MSM (Haghighat et al., 2008). The yeast consortium $\mathrm{YC} 02$ was inoculated in $500 \mathrm{~mL}$ Erlenmeyer flasks containing $150 \mathrm{~mL} \mathrm{MSM}$ of initial $\mathrm{pH} 7.0$ and incubated at $30^{\circ} \mathrm{C}$ for 3 days under shaking condition of $130 \mathrm{rpm}$.

Biosurfactant production by YC02 in MSM was confirmed by various tests viz. drop collapsing test (Bodour and Miller-Maier, 1998), methylene blue agar plate method (Satpute et al., 2008) and emulsification test ( $\left.\mathrm{E}_{24}\right)$ (Bodour et al., 2004) following the standard procedures.

\section{Biodegradation of PRL in presence of $\mathrm{ZnO}$ nanoparticles and produced biosurfactant}

The biodegradation experiments were conducted in sterilized $500 \mathrm{~mL}$ Erlenmeyer flask containing $100 \mathrm{~mL}$ of sterilized mineral salt medium supplemented with PRL (50 mg L $\mathrm{m}^{-1}$ ) under different set of conditions as follows : (i) PRL + YC02 (ii) $\mathrm{PRL}+\mathrm{YC} 02+$ produced biosurfactant (iii) $\mathrm{PRL}+\mathrm{YC} 02+\mathrm{ZnO}$ nanoparticles $\left(0.5 \mathrm{~g} \mathrm{~L}^{-1}\right)$ (iv) $\mathrm{PRL}+\mathrm{YC} 02+$ produced biosurfactant $+\mathrm{ZnO}$ nanoparticles $(0.5 \mathrm{~g}$ $\left.\mathrm{L}^{-1}\right)$. Flasks without inoculation were maintained as control. The residual PRL was extracted from the different set of conditions and biodegradation percentage was calculated.

\section{Instrumental analysis}

GC-MS analysis was done to determine the residual PRL and the degraded products in the culture broths (Arulazhagan et al., 2010). Flasks from different set of conditions were withdrawn after 6 days of incubation. The degraded products were extracted using ethyl acetate. The solvent was removed under vacuum by rotary evaporation (Superfit ${ }^{\mathrm{TM}}$ Rotary vacuum Digital bath) prior to analysis. Aliquots of $2-5 \mu \mathrm{L}$ were injected directly for GC-MS analysis, (JEOL GC MATEII) using silica as stationary phase. The inlet temperature was $220^{\circ} \mathrm{C}$; oven temperature was increased from 50 to $250^{\circ} \mathrm{C}$ at $10^{\circ} \mathrm{C}$ rev $\mathrm{min}^{-1}$; the GC interface temperature was $250^{\circ} \mathrm{C}$; carrier gas was nitrogen at a flow rate of 1.0 $\mathrm{mL}$ rev $\mathrm{min}^{-1}$. Mass spectrum conditions had the ionization energy $70 \mathrm{eV}$, ion chamber temperature was maintained at $250^{\circ} \mathrm{C}$ with tungsten filament which was used for the ionization of molecules. The concentration of PRL was calculated by comparing the peak areas of each treated sample with that of the peak area of the abiotic control. For identification of the degraded products, the mass spectra of the products formed were compared with respective mass spectra of authentic compounds and also with the mass profile of the same compound available in the National Institute of Standard Technology (NIST) library, USA.

The FTIR spectra of PRL and degraded products were used to determine the vibrational frequency changes in functional groups. The extended degraded products dissolved in ethyl acetate, were mixed with $\mathrm{KBr}$ and made in the form of pellets (13 $\mathrm{mm}$ in diameter and $1 \mathrm{~mm}$ thickness). IR spectroscopy was investigated with the IR affinity-1 FT-IR spectrophotometer (Shimadzu). The scanning wavenumber ranged from 4,000 to $400 \mathrm{~cm}^{-1}$ and the spectral resolution was $4 \mathrm{~cm}^{-1}$.

\section{Process optimization}

Response surface methodology (RSM) using Box-Behnken design (BBD) was used for optimization of parameters and to determine the significant single factors, interactions and quadratic terms. Each factor was varied at three different levels $-1,0$ and +1 signifying low, medium and high values. The minimum and maximum ranges of $\mathrm{pH}$, temperature, shaking speed, inoculum dosage and zinc oxide nanoparticle concentrations were determined as shown in Table 1. A design of 46 experiments were formulated and the experiments were carried out in 250 $\mathrm{mL}$ Erlenmeyer flasks containing $100 \mathrm{~mL}$ of production medium (PRL $50 \mathrm{mg} \mathrm{L}$ $\left.{ }^{1}\right)$. The experiments were performed twice to optimize the levels of the selected variables viz., $\mathrm{pH}(\mathrm{A})$, temperature (B), shaking speed (C), inoculum dosage (D) and zinc oxide nanoparticle concentrations (E). The range of the variables was chosen based on preliminary experiments. The $3 \mathrm{D}$ contour plots were prepared to evaluate the optimized parameters, which influence the response. The respective responses were analyzed by using a second order polynomial equation, and the data were fitted to the equation by multiple regression procedures. Later, an experiment was conducted in triplicates using the optimum values for variables given by response surface optimization to validate the predicted value and the observed value of the responses. The results of the experimental design were analyzed and interpreted using Design-Expert version 11.0 (Stat-Ease Inc. Minneapolis, MN, USA) statistical software (Sahoo and Gupta, 2012).

Table 1 Independent factors and its level used in response surface design for PRL biodegradation

\begin{tabular}{llccc}
\hline Factors & Name & Level $(0)$ & Low level(-1) & High level $(+1)$ \\
\hline $\mathrm{A}$ & $\mathrm{pH}$ & 7 & 5 & 9 \\
$\mathrm{~B}$ & Temperature $\left({ }^{\circ} \mathrm{C}\right)$ & 30 & 10 & 50 \\
$\mathrm{C}$ & Shaking speed $(\mathrm{rpm})$ & 130 & 110 & 150 \\
$\mathrm{D}$ & Inoculum dosages $(\%)$ & 3 & 1 & 5 \\
$\mathrm{E}$ & ZnO nanoparticle concentration $\left(\mathrm{g} \mathrm{L}^{-1}\right)$ & 2 & 1 & 3 \\
\hline
\end{tabular}

\section{Kinetic studies}

Degradation kinetics was performed in triplicates. The zero order (Wang $\boldsymbol{e t} \boldsymbol{a l}$. 2002), first order (Agarry et al., 2013) and second order (Capellos and Bielski, 1972) kinetic models were used to define the degradation of PRL in mineral medium.

\section{RESULTS AND DISCUSSION}

\section{Characterization of $\mathrm{ZnO}$ nanoparticles}

\section{UV-Visible Spectroscopy analysis of $\mathrm{ZnO}$ nanoparticles}

The optical characterization of the sample was recorded on UV-Vis absorption spectrophotometer showed in Figure 1a. The UV-Visible absorption spectroscopy of $\mathrm{ZnO}$ nanoparticles in deionized water exhibited maximum absorption at two different wavelengths of $240 \mathrm{~nm}$ and $390 \mathrm{~nm}$ which clearly indicated the gradual formation of $\mathrm{ZnO}$ nanoparticles. Similar result was reported by Kulkarni and Shirsat (2015).

\section{XRD analysis of $\mathrm{ZnO}$ nanoparticles}

The XRD pattern of $\mathrm{ZnO}$ nanoparticle exhibited well-defined peaks at $2 \theta$ values of $13.13,15.28,26.13,26.90,33.31,38.94$ and 59.69 which correspond to the $010,011,113,104,213,123$ and 401 planes respectively (Figure 1b). The intensity of $\mathrm{ZnO}$ nanoparticle peaks at $2 \theta$ values of $15.28,26.90,33.31$ and 59.69 reflected high degree of crystallinity in nanoparticles. Similar result was demonstrated by Kumar and Rani (2013).

\section{FTIR analysis of $\mathrm{ZnO}$ nanoparticles}

The FTIR spectrum of dispersed $\mathrm{ZnO}$ nanoparticles in deionized water was shown in Figure 1c. Infrared studies were carried out in order to ascertain the purity and nature of the zinc oxide nanoparticles. Metal oxides generally give absorption bands in fingerprint region i.e. below $1000 \mathrm{~cm}^{-1}$ arising from interatomic vibrations. The peaks at observed at $3257.77,3165.19,3101.54 \mathrm{~cm}^{-1}$ were due to $\mathrm{O}-\mathrm{H}$ stretching vibration arising from hydroxyl groups from the water on nanoparticles. The absorption peaks at 1548.84, 1498.69, 1361.03, 1354.03, 1039.63 and $947.05 \mathrm{~cm}^{-1}$ were due to de-ionized water used as solvent. The absorption peaks at $690.52,514.99,480.29 \mathrm{~cm}^{-1}$ were corresponding to the $\mathrm{Zn}-\mathrm{O}$ bond stretching and deformation vibration, respectively. Similar FTIR spectra were observed in case of zinc oxide nanoparticles (Parthasarathi and Thilagavathi, 2011; Kumar and Rani, 2013).

\section{TEM and EDX analysis of $\mathrm{ZnO}$ nanoparticles}

The morphological and structural properties of the prepared nanoparticle are illustrated in the TEM images (Figure 1d). The $\mathrm{ZnO}$ nanoparticle particles are highly agglomerated with roughly the average particle size of $45 \mathrm{~mm}$. The elemental analysis of $\mathrm{ZnO}$ nanoparticle was performed using energy dispersive 
X-ray (EDX) analysis (Figure 1e). The EDX spectrum of $\mathrm{ZnO}$ nanoparticle indicated the presence of $\mathrm{Zn}$ and $\mathrm{O}$ as present on $\mathrm{ZnO}$ nanoparticle. The peak of

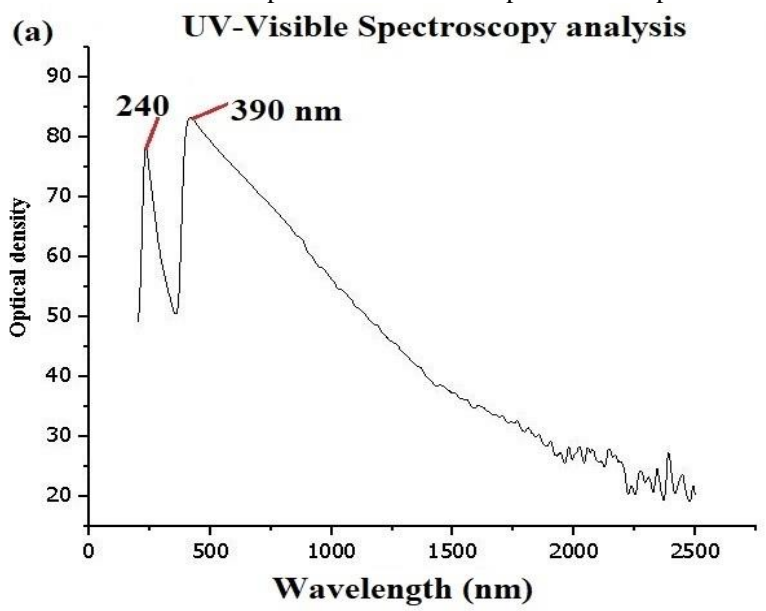

(c)

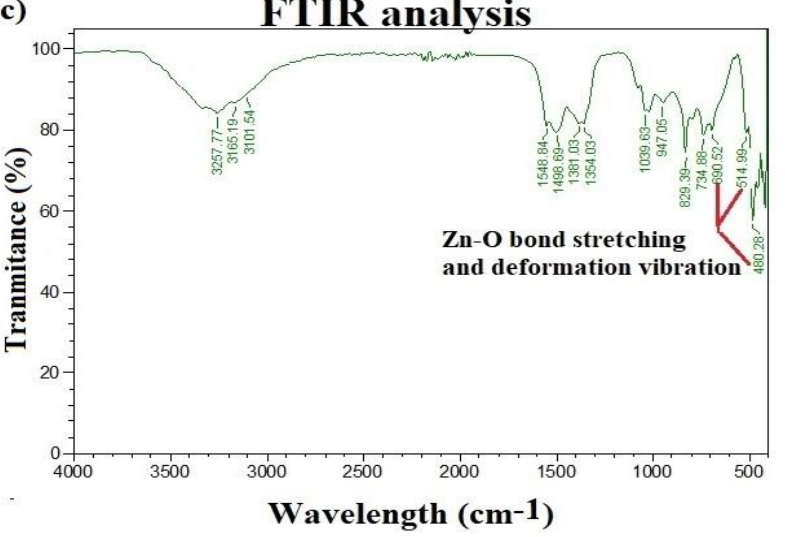

$\mathrm{Zn}$ and $\mathrm{O}$ were noted on EDX which confirmed $\mathrm{ZnO}$ nanoparticle.

(b)

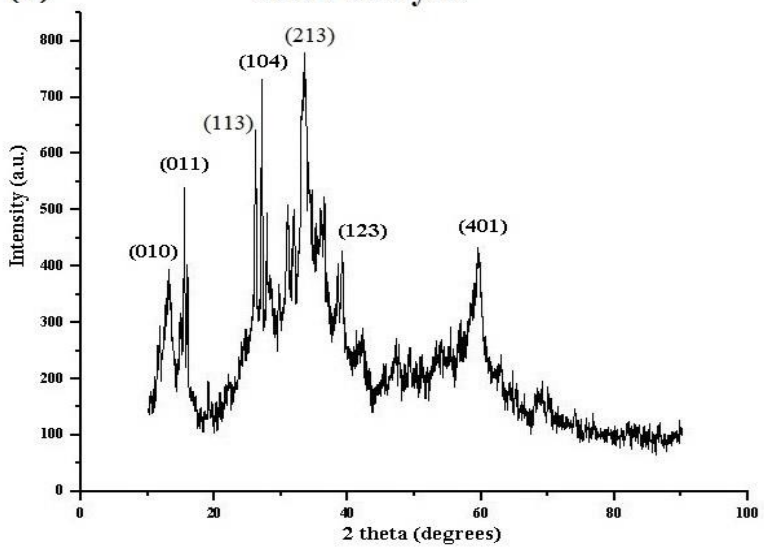

(d) TEM micrograph

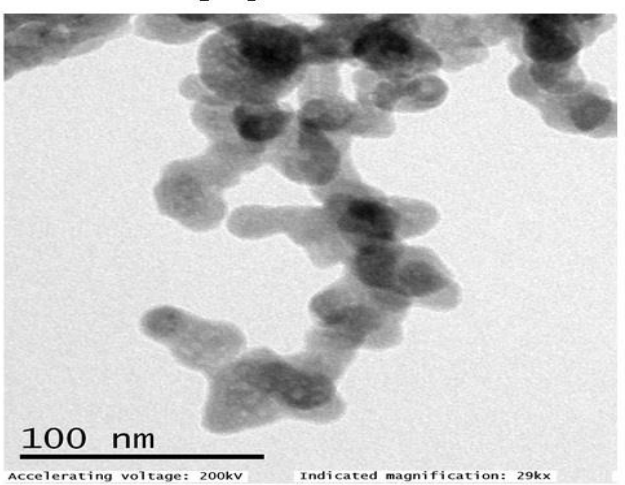

EDX analysis

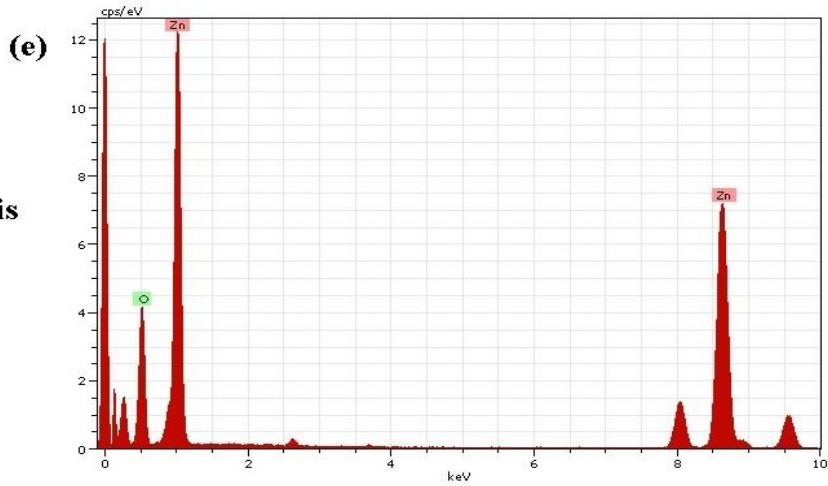

Figure 1 Characterization of ZnO nanoparticle: (a)UV-Visible Spectroscopy analysis of ZnO nanoparticle, (b) XRD analysis of synthesized ZnO nanoparticles, (c) FTIR analysis of synthesized $\mathrm{ZnO}$ nanoparticle, (d) TEM micrographs of synthesized $\mathrm{ZnO}$ nanoparticle and (e) EDX of synthesized ZnO nanoparticle.

\section{Biosurfactant production}

Biosurfactant produced by yeast consortium (YC02) in the MS medium was tested by methylene blue agar test, drop collapsing test and emulsification index $(\%)$. The positive results of all the tests confirmed the biosurfactant producing ability of YC02. The flat drop appearance in micro titer plate confirmed the positive results for drop collapse test. Dark blue halo zone in the methylene blue agar plate supplemented with CTAB confirmed the presence of anionic biosurfactant (Figure not shown). The emulsification index was found to be $61.7 \%$.

\section{GC-MS analysis for PRL biodegradation}

The degradation of PRL $\left(50 \mathrm{mg} \mathrm{L}^{-1}\right)$ by yeast consortium YC02 in MSM was found to be $67.0 \%$ after 6 days of incubation. Improvement in degradation $(68.3 \%)$ was noted when MSM was supplemented with $\mathrm{ZnO}$ nanoparticles $(0.5 \mathrm{~g}$ $\left.\mathrm{L}^{-1}\right)$. Maximum degradation of PRL $(70.0 \%)$ was observed in presence of $\mathrm{ZnO}$ nanoparticles $\left(0.5 \mathrm{~g} \mathrm{~L}^{-1}\right)$ and produced biosurfactant in MSM (Figure 2a). This implementation proved that $\mathrm{ZnO}$ nanoparticles were capable of assisting the microbial activities which agree with other studies (Shin and Cha, 2008). Hesham et al. (2006) reported the degradation of PRL $\left(6.03 \mathrm{mg} \mathrm{Kg}^{-1}\right)$ by a mixture of five yeast strains which was found to be $70 \%$ after a period of 42 days. The soil fungi viz. Aspergillus sp. and Achremonium sp. were also reported to be capable of degrading PRL $37.0 \%$ and $20.5 \%$ respectively after a period of 30 days at the concentration $0.05\left(\mathrm{w} \mathrm{v}^{-1}\right)$ (Silva et al., 2009). Therefore, yeast consortium $\mathrm{YC} 02$ used in the present study was found to be more efficient in degrading PRL at much higher concentration $\left(50 \mathrm{mg} \mathrm{L}^{-1}\right)$ within a short period $(6$ days) compared to the earlier reports. According to the Figure 2a, it can be concluded that the presence of $\mathrm{ZnO}$ nanoparticles could enhance the ability of yeast consortium YC02 in terms of improving the biosurfactant properties which followed by enhancing the biodegradation process. So far, extremely limited studies have been reported on combined effect of nanoparticles and biosurfactant towards degradation of environmental pollutants (Zhang et al., 2011).

\section{FT-IR analysis}

FTIR spectra of control perylene (Figure 2b) showed the characteristic absorption peaks at $3047 \mathrm{~cm}^{-1}$ (=CH stretch in aromatic rings), 2850.79-2953.02 $\mathrm{cm}^{-1}$ (C-H stretching in cyclic ring), $1741.72-1921.1 \mathrm{~cm}^{-1}$ (weak overtone and combination bands in aromatic compounds), $1490.97-1587.42 \mathrm{~cm}^{-1}$ (variable aromatic ring stretching), $759.75-885.33 \mathrm{~cm}^{-1}$ (strong out of plane $\mathrm{CH}$ deformations in aromatic compounds) and 462.92-540.07 $\mathrm{cm}^{-1}$ (ring deformations in aromatic compounds). The second spectra illustrated, degraded perylene products by yeast consortium, YC02 showed a presence of 2970.38-2796.78 $\mathrm{cm}^{-1}$ representing $\mathrm{H}$-bonded $\mathrm{OH}$ stretch in carboxylic acid. Sharp absorption peak of $1739.79 \mathrm{~cm}^{-1}$ (overtone and combination bonds in aromatic compounds), $1637.56 \mathrm{~cm}^{-1}$ (C=O stretching, enol 
form in $\beta$-kentone esters ), $1537.27 \mathrm{~cm}^{-1}$ (aromatic ring stretching), $1427.32 \mathrm{~cm}^{-1}$ (in plane $\mathrm{OH}$ bonding in carboxylic acids), $1369.46 \mathrm{~cm}^{-1}$ (medium $\mathrm{CH}_{3}$ deformations in isopropyl groups), $1215.15 \mathrm{~cm}^{-1}$ (C-O-C antisym stretch in vinyl ethers), $1004.91 \mathrm{~cm}^{-1}$ (ring breathing mode of carbon ring in cyclic compounds), $954.76 \mathrm{~cm}^{-1}$ (=CH out of plane deformation in vinyl compounds), $615.29 \mathrm{~cm}^{-1}$ (C-OH out of plane deformations in alcohols) and 572.86-534.28 $\mathrm{cm}^{-1}$ (ring deformations in aromatic compounds). These results suggest that the parental compound has undergone significant changes after degradation.

\section{Process optimization}

A statistical tool, three level 5 variables Box-Behnken Design was implemented to enhance the biodegradation of PRL using yeast consortium (YC02). The

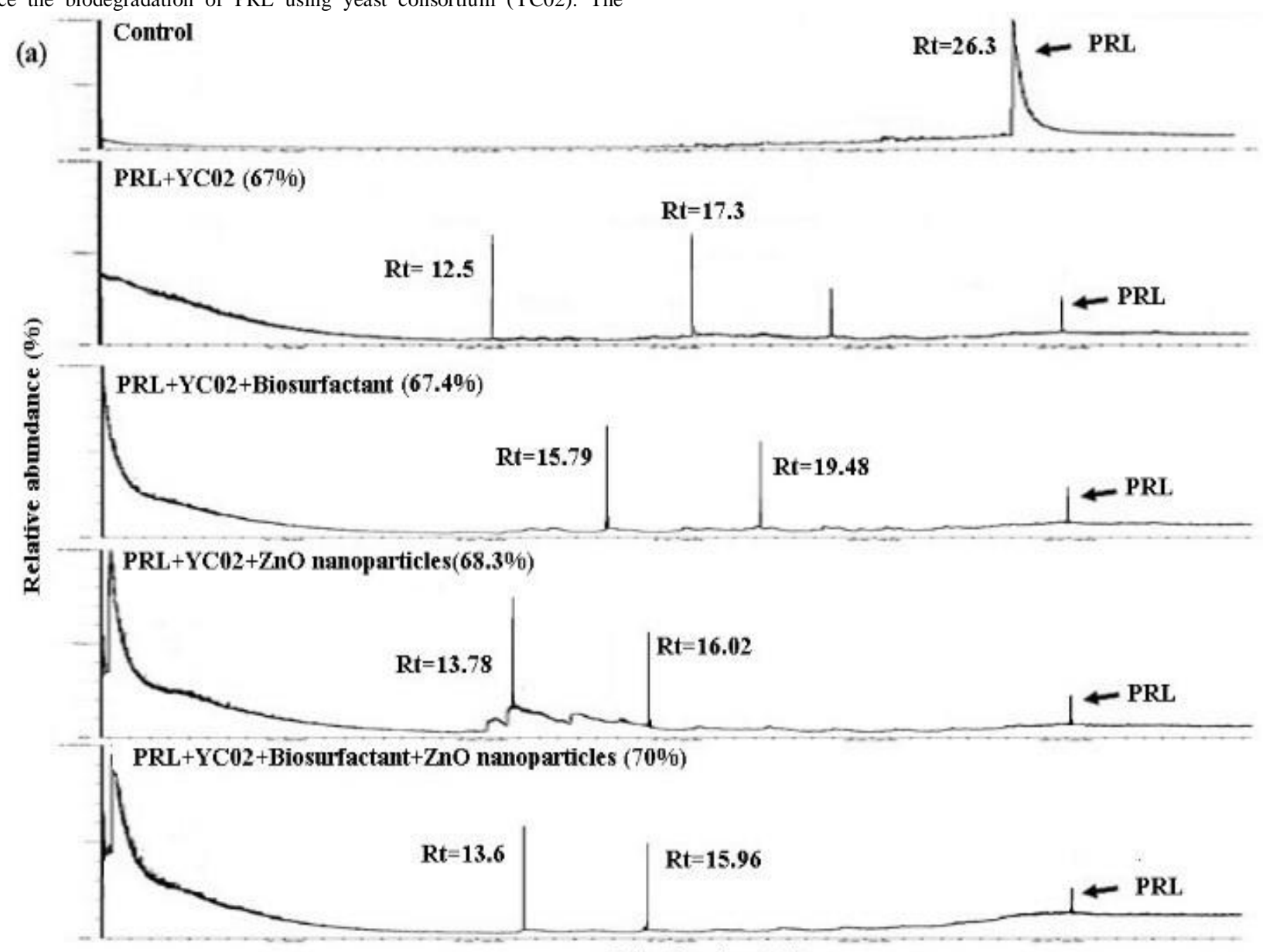

Retention time (Rt)
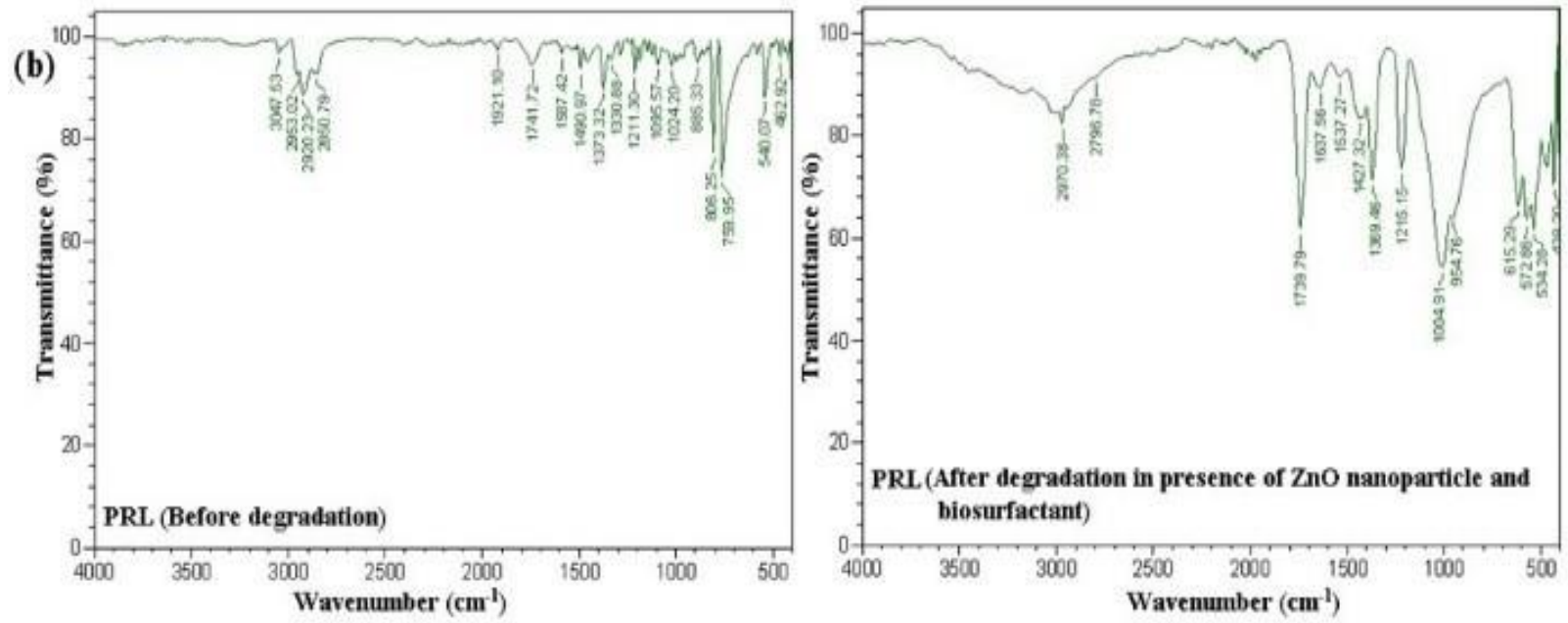

Figure 2 (a) GC-MS analysis of PRL degradation under different sets of condition after 6 days. (b) FT-IR spectrum of PRL before degradation and after degradation in presence of $\mathrm{ZnO}$ nanoparticle and biosurfactant.

The total determination coefficient R-Squared value was found to be 0.9790 , indicating a realistic fit of the model to the experimental data (Table 2). This also indicates that $97 \%$ variation of response can be elucidated effectively and approves that $3 \%$ of the variations occur while performing the experiments. The factors were optimized by BBD with six central points, the response PLR biodegradation $(\%)$ was studied and the second-order polynomial equation was given below:

$-0.5625 \mathrm{E}+3.25 \mathrm{AB}+$ $3.00 \mathrm{AC}-1.50 \mathrm{AD}+3.25 \mathrm{AE}-0.25 \mathrm{BC}+1.25 \mathrm{BD}+0.75 \mathrm{BE}+0.25 \mathrm{CD}-2.5 \mathrm{CE}$ $+1.25 \mathrm{DE}-5.19 \mathrm{~A}^{2}-5.52 \mathrm{~B}^{2}-7.35 \mathrm{C}^{2}-4.44 \mathrm{D}^{2}-3.44 \mathrm{E}^{2}$

Where, $\mathrm{Y}$ was representing PRL biodegradation (\%) as response and $\mathrm{A}, \mathrm{B}, \mathrm{C}, \mathrm{D}$ and $\mathrm{E}$ were coded terms for the five test variables viz. $\mathrm{pH}$, temperature, shaking speed, inoculum dosages and $\mathrm{ZnO}$ nanoparticle concentration respectively. The lack of fit analysis was found to be not significant which considered that the model is fit. 
biodegradation, as compared to temperature, shaking speed and inoculum dosages. When considered with respect to squared terms, all the variables had positive significance on PRL biodegradation as tabulated in Table 2. The interactive effect of variables, $\mathrm{AB}, \mathrm{AC}, \mathrm{AD}, \mathrm{AE}, \mathrm{BD}, \mathrm{CE}$ and $\mathrm{DE}$ were found to be the most significant in response as shown in Figure 3. In Figure 3a, the response plot $\mathrm{AB}$ ( $\mathrm{pH}$ vs temperature) indicated a significant reduction from acidic to alkaline $\mathrm{pH}$ and from lower $\left(10^{\circ} \mathrm{C}\right)$ to higher temperature on PRL biodegradation. The maximum PRL biodegradation was observed at $\mathrm{pH} 7$ and at temperature of $30^{\circ} \mathrm{C}$. The response plots of $\mathrm{AD}$ ( $\mathrm{pH}$ vs inoculum dosages) and $\mathrm{BD}$ (temperature vs inoculum dosages) were found to be significant and maximum degradation was observed at 3\% inoculum as shown in Figure 3c, e. The response plots of $\mathrm{AC}$ ( $\mathrm{pH}$ vs shaking speed) was found to be significant and maximum degradation was observed at $120 \mathrm{rpm}$ as shown in Figure $3 \mathrm{~b}$.

Design-Expert Software
Trial Version
Factor Coding:Actual
Design points above predicted value
ODesign points below predicted value
59
$\mathrm{X} 1=\mathrm{A}: \mathrm{pH}$
$\mathrm{X} 2=\mathrm{B}:$ Temperature
Actual factors
$\mathrm{C}:$ Shaking speed $=130$
$\mathrm{D}:$ Dosage $=3$
E:ZnO nanoparticles:

(a)

$\mathrm{X} 1=\mathrm{A}: \mathrm{pH}$
$\mathrm{X} 2=\mathrm{D}:$ Dosage
Actual Factors
B:Temperature $=30$
C:Shaking speed=130
E:ZnO nanoparticles

(c)

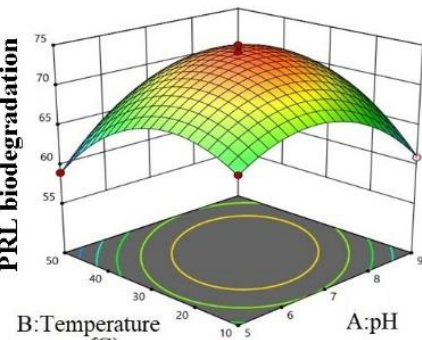

(C)

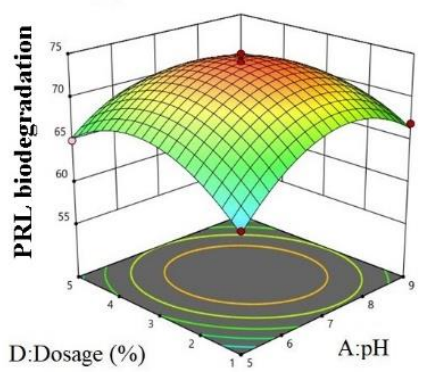

$\mathrm{Xl}=\mathrm{B}:$ Temperature $\mathrm{X} 2=\mathrm{D}$ :Dosage

Actual Factors

$\mathrm{A}: \mathrm{pH}=7$

C:Shaking speed $=130$

$\mathrm{E}: \mathrm{ZnO}$ nanoparticles $=2$

(e)

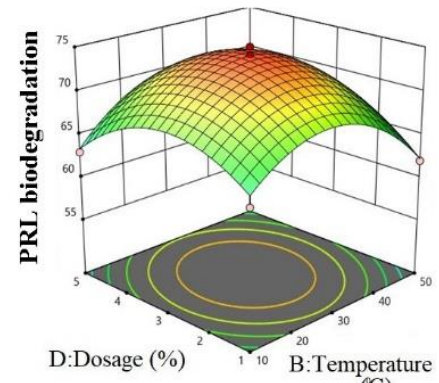

(C)

$\mathrm{X} 1=\mathrm{D}:$ Dosage $\mathrm{X} 2=\mathrm{E}: \mathrm{ZnO}$ nanoparticles

Actual Factors

A:pH=

B: $:$ emperature $=30$

C:Shaking speed $=130$

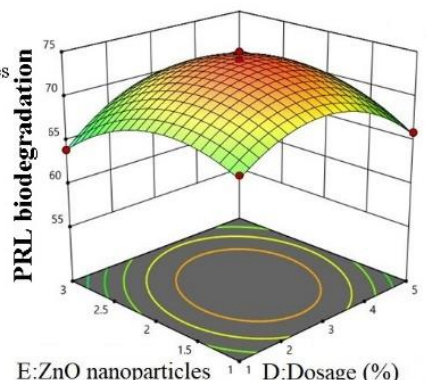

E: $\mathrm{ZnO}$ nanoparticles $11 \mathrm{D}:$ Dosage (\%)

$(\mathrm{g} / \mathrm{L})$
$\mathrm{X} 1: \mathrm{A}: \mathrm{pH}$

$\mathrm{X} 2$ :D:Dosages

Actual factors

B $:$ Temperature $=30$

C: Shaking speed $=130$

$\mathrm{E}: \mathrm{ZnO}$ nanoparticles $=2$

(b)

$\mathrm{X} 1=\mathrm{A}: \mathrm{pH}$

$\mathrm{X} 2=\mathrm{ZnOnanoparticles}$

Actual Factors

B: Temperature $=30$

C: Shaking speed $=130$

D:Dosage $=3$

(d)

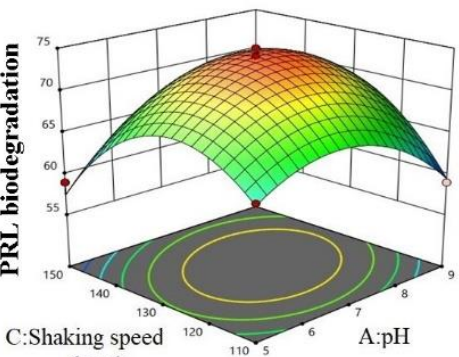

(rpm)

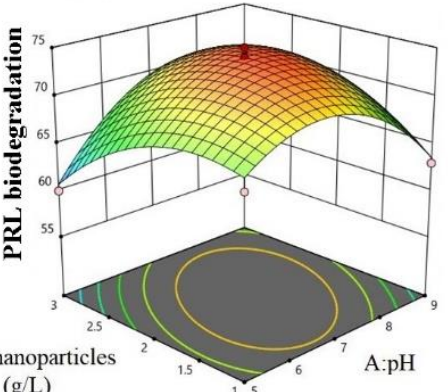

$\mathrm{E}: \mathrm{ZnO}$ nano

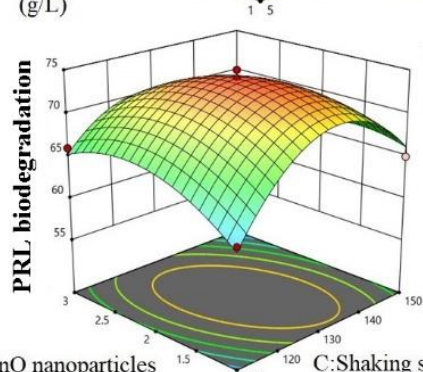

(f)

$(\mathrm{g} / \mathrm{L})$
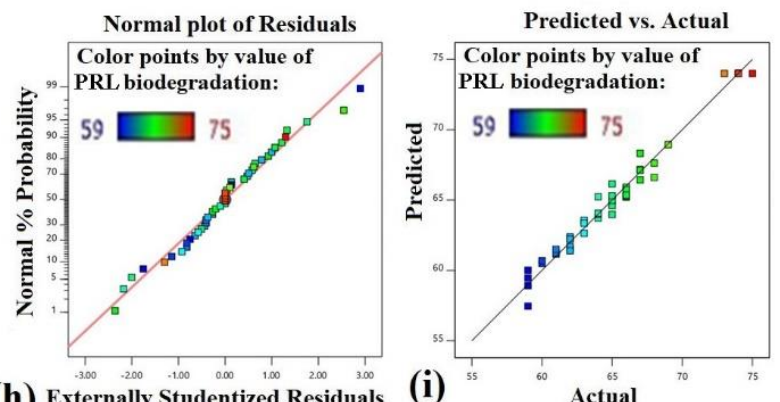

Figure 3 3-D interactions between the different variables for response (PRL biodegradation \%) where, (a) pH vs. Temperature (AB) (b) pH vs. Shaking speed (AC)

(c) $\mathrm{pH}$ vs. Dosage (AD) (d) pH vs. ZnO nanoparticles (AE) (e) Temperature vs. Dosage (BD) (f) Shaking speed vs. ZnO nanoparticles (CE) (g) Dosage vs. ZnO nanoparticles (DE) (h) Normal plot of residuals (i) Predicted vs. actual plot.

The response plot of $\mathrm{AE}$ ( $\mathrm{pH}$ vs $\mathrm{ZnO} \mathrm{Nps}$ ), $\mathrm{CE}$ (shaking speed vs $\mathrm{ZnO} \mathrm{Nps}$ ) and $\mathrm{DE}$ (inoculum dosage vs $\mathrm{ZnO} \mathrm{Nps}$ ) were found to be significant and maximum PRL biodegradation was observed at $2.0 \mathrm{gL}^{-1} \mathrm{ZnO}$ nanoparticle as shown in Figure $3 \mathrm{~d}, \mathrm{f}, \mathrm{g}$. The supplementation of $\mathrm{ZnO}$ nanoparticle in the production medium had showed significant impact on PRL biodegradation (\%) using the yeast consortium. However, a significant reduction in the PRL degradation was observed at higher concentration of $\mathrm{ZnO}$ nanoparticles $\left(3 \mathrm{~g} \mathrm{~L}^{-1}\right)$. This could be because of the addition of high amount of $\mathrm{ZnO}$ Nps which become toxic to yeast cells. Similar trend by El-Sheshtawy and Ahmed (2017) was reported where crude oil was degraded using Bacillus licheniformis in the presence of different concentration nanoparticles and produced biosurfactant. 
Table 2 ANOVA for Response Surface Quadratic Model (Response: PRL biodegradation \%)

\begin{tabular}{|c|c|c|c|c|c|c|}
\hline Source & Sum of Squares & df & Mean Square & F-value & p-value & \\
\hline Model & 852.64 & 20 & 42.63 & 58.13 & $<0.0001$ & significant \\
\hline $\mathrm{A}-\mathrm{Ph}$ & 12.25 & 1 & 12.25 & 16.70 & 0.0004 & significant \\
\hline B-Temperature & 1.00 & 1 & 1.00 & 1.36 & 0.2539 & \\
\hline C-Shaking speed & 0.25 & 1 & 0.25 & 0.34 & 0.5645 & \\
\hline D-Dosage & 1.56 & 1 & 1.56 & 2.13 & 0.1568 & \\
\hline E-ZnO nanoparticle & 5.06 & 1 & 5.06 & 6.90 & 0.0145 & significant \\
\hline $\mathrm{AB}$ & 42.25 & 1 & 42.25 & 57.61 & $<0.0001$ & significant \\
\hline $\mathrm{AC}$ & 36.00 & 1 & 36.00 & 49.09 & $<0.0001$ & significant \\
\hline $\mathrm{AD}$ & 9.00 & 1 & 9.00 & 12.27 & 0.0018 & significant \\
\hline $\mathrm{AE}$ & 42.25 & 1 & 42.25 & 57.61 & $<0.0001$ & significant \\
\hline $\mathrm{BC}$ & 0.25 & 1 & 0.25 & 0.3409 & 0.5645 & \\
\hline $\mathrm{BD}$ & 6.25 & 1 & 6.25 & 8.52 & 0.0073 & significant \\
\hline $\mathrm{BE}$ & 2.25 & 1 & 2.25 & 3.07 & 0.0921 & \\
\hline CD & 0.2500 & 1 & 0.2500 & 0.3409 & 0.5645 & \\
\hline $\mathrm{CE}$ & 25.00 & 1 & 25.00 & 34.09 & $<0.0001$ & significant \\
\hline $\mathrm{DE}$ & 6.25 & 1 & 6.25 & 8.52 & 0.0073 & significant \\
\hline $\mathrm{A}^{2}$ & 234.85 & 1 & 234.85 & 320.25 & $<0.0001$ & significant \\
\hline $\mathrm{B}^{2}$ & 266.00 & 1 & 266.00 & 362.73 & $<0.0001$ & significant \\
\hline $\mathrm{C}^{2}$ & 472.00 & 1 & 472.00 & 643.64 & $<0.0001$ & significant \\
\hline $\mathrm{D}^{2}$ & 171.85 & 1 & 171.85 & 234.34 & $<0.0001$ & significant \\
\hline$E^{2}$ & 103.12 & 1 & 103.12 & 140.62 & $<0.0001$ & significant \\
\hline Residual & 18.33 & 25 & 0.7333 & & & \\
\hline Lack of Fit & 16.33 & 20 & 0.8167 & 2.04 & 0.2201 & not significant \\
\hline Pure Error & 2.00 & 5 & 0.4000 & & & \\
\hline Cor Total & 870.98 & 45 & & & & \\
\hline Std. Dev. & 0.8563 & & & & & \\
\hline Mean & 64.98 & & & & & \\
\hline C.V. \% & 1.32 & & & & & \\
\hline $\mathrm{R}^{2}$ & 0.9790 & & & & & \\
\hline Adjusted $\mathrm{R}^{2}$ & 0.9621 & & & & & \\
\hline Predicted $\mathrm{R}^{2}$ & 0.9217 & & & & & \\
\hline Adeq Precision & 28.5889 & & & & & \\
\hline
\end{tabular}

A statistical model was validated by executing point prediction tool of BBD from an optimum value of all the 5 variables A, B, C, D and E. The actual PRL biodegradation $(74.00 \pm 0.01 \%)$ was in close agreement with the predicted value $(74.00 \pm 0.8 \%)$ indicating the validity of the model (Table 3). Maximum biodegradation of PRL was found to be $74.0 \pm 0.01(\%)$ at central values of al the factors viz., $\mathrm{pH}(7.0)$, temperature $\left(30^{\circ} \mathrm{C}\right)$, shaking speed $(130 \mathrm{rpm}), \mathrm{ZnO}$ nanoparticle $\left(2 \mathrm{~g} \mathrm{~L}^{-1}\right)$ and inoculum dosages $(3 \%)$. The normal plot for residuals and predicted vs actual plots were represented (Figure $3 \mathrm{~h}-\mathrm{i}$ ) respectively. Thus, the biodegradation of PRL by YC02 was found to be increased from $70.0 \%$ to $74.0 \%$ in aqueous medium under optimized condition using BBD.

Table 3 Actual versus predicted value for Response: PRL biodegradation (\%)

\begin{tabular}{|c|c|c|c|c|c|c|c|c|}
\hline Std & Run & $\begin{array}{l}\text { Factor } 1 \\
\mathrm{~A}: \mathrm{Ph}\end{array}$ & $\begin{array}{l}\text { Factor } 2 \\
\text { B:Temperature } \\
\text { (degree) }\end{array}$ & $\begin{array}{l}\text { Factor } 3 \\
\text { C:Shaking } \\
\text { speed (rpm) }\end{array}$ & $\begin{array}{l}\text { Factor } 4 \\
\text { D: Dosage } \\
(\%)\end{array}$ & $\begin{array}{l}\text { Factor } 5 \\
\text { E:ZnO } \\
\text { nanoparticle (g L- } \\
\left.{ }^{1}\right)\end{array}$ & $\begin{array}{l}\text { Response: PRL } \\
(\%) \\
\text { Actual value }\end{array}$ & $\begin{array}{l}\text { biodegradation } \\
\text { Predicted } \\
\text { values }\end{array}$ \\
\hline 42 & 1 & 0 & 0 & 0 & 0 & 0 & 74 & 74.00 \\
\hline 6 & 2 & 0 & 0 & 1 & -1 & 0 & 62 & 61.52 \\
\hline 24 & 3 & 0 & 1 & 1 & 0 & 0 & 60 & 60.50 \\
\hline 44 & 4 & 0 & 0 & 0 & 0 & 0 & 74 & 74.00 \\
\hline 16 & 5 & 1 & 0 & 1 & 0 & 0 & 66 & 65.21 \\
\hline 9 & 6 & 0 & -1 & 0 & 0 & -1 & 68 & 66.60 \\
\hline 3 & 7 & -1 & 1 & 0 & 0 & 0 & 59 & 58.92 \\
\hline 29 & 8 & 0 & 0 & -1 & 0 & -1 & 62 & 61.40 \\
\hline 36 & 9 & 1 & 0 & 0 & 0 & 1 & 69 & 68.94 \\
\hline 20 & 10 & 0 & 0 & 0 & -1 & 1 & 67 & 67.13 \\
\hline 33 & 11 & -1 & 0 & 0 & 0 & -1 & 67 & 68.31 \\
\hline 13 & 12 & -1 & 0 & -1 & 0 & 0 & 64 & 63.71 \\
\hline 17 & 13 & 0 & 0 & 0 & -1 & -1 & 68 & 67.63 \\
\hline 28 & 14 & 1 & 0 & 0 & 1 & 0 & 62 & 62.23 \\
\hline 27 & 15 & -1 & 0 & 0 & 1 & 0 & 65 & 65.31 \\
\hline 39 & 16 & 0 & -1 & 0 & 1 & 0 & 63 & 63.35 \\
\hline 25 & 17 & -1 & 0 & 0 & -1 & 0 & 62 & 61.69 \\
\hline 8 & 18 & 0 & 0 & 1 & 1 & 0 & 63 & 62.65 \\
\hline 41 & 19 & 0 & 0 & 0 & 0 & 0 & 73 & 74.00 \\
\hline 21 & 20 & 0 & 0 & -1 & 0 & 0 & 61 & 61.25 \\
\hline 45 & 21 & 0 & 0 & 0 & 0 & 0 & 75 & 74.00 \\
\hline 46 & 22 & 0 & 0 & 0 & 0 & 0 & 74 & 74.00 \\
\hline 15 & 23 & -1 & 0 & 1 & 0 & 0 & 59 & 57.46 \\
\hline 2 & 24 & 1 & -1 & 0 & 0 & 0 & 61 & 61.17 \\
\hline 12 & 25 & 0 & 1 & 0 & 0 & 1 & 65 & 64.98 \\
\hline 35 & 26 & -1 & 0 & 0 & 0 & 1 & 60 & 60.69 \\
\hline 1 & 27 & -1 & -1 & 0 & 0 & 0 & 66 & 65.92 \\
\hline 34 & 28 & 1 & 0 & 0 & 0 & -1 & 63 & 63.56 \\
\hline 43 & 29 & 0 & 0 & 0 & 0 & 0 & 74 & 74.00 \\
\hline 31 & 30 & 0 & 0 & -1 & 0 & 1 & 66 & 65.27 \\
\hline 10 & 31 & 0 & 1 & 0 & 0 & -1 & 65 & 64.60 \\
\hline 30 & 32 & 0 & 0 & 1 & 0 & -1 & 65 & 66.15 \\
\hline 11 & 33 & 0 & -1 & 0 & 0 & 1 & 65 & 63.98 \\
\hline
\end{tabular}




\begin{tabular}{|c|c|c|c|c|c|c|c|c|}
\hline 40 & 34 & 0 & 1 & 0 & 1 & 0 & 66 & 65.35 \\
\hline 4 & 35 & 1 & 1 & 0 & 0 & 0 & 67 & 67.17 \\
\hline 14 & 36 & 1 & 0 & -1 & 0 & 0 & 59 & 59.46 \\
\hline 18 & 37 & 0 & 0 & 0 & 1 & -1 & 66 & 65.75 \\
\hline 22 & 38 & 0 & 1 & -1 & 0 & 0 & 61 & 61.25 \\
\hline 32 & 39 & 0 & 0 & 1 & 0 & 1 & 59 & 60.02 \\
\hline 38 & 40 & 0 & 1 & -1 & -1 & 0 & 62 & 62.23 \\
\hline 23 & 41 & 0 & -1 & 1 & 0 & 0 & 61 & 61.50 \\
\hline 5 & 42 & 0 & 0 & -1 & -1 & 0 & 62 & 62.27 \\
\hline 19 & 43 & 0 & 0 & 0 & -1 & 1 & 64 & 64.00 \\
\hline 7 & 44 & 0 & 0 & -1 & 1 & 0 & 62 & 62.40 \\
\hline 26 & 45 & 1 & 0 & 0 & -1 & 0 & 67 & 66.44 \\
\hline 37 & 46 & 0 & 0 & 0 & -1 & 0 & 64 & 65.23 \\
\hline
\end{tabular}

\section{Kinetic studies}

The kinetic study was performed applying the predicted optimum conditions. The kinetic data on degradation of PRL $\left(50 \mathrm{mg} \mathrm{L}^{-1}\right)$ was best fitted with the first order kinetic model in case of all set of conditions. The highest regression coefficient $\left(\mathrm{R}^{2}\right)$ values of $(0.9938)$ of PRL degradation was noted in case of biosurfactant producing $\mathrm{YCO} 2$ in presence of $\mathrm{ZnO}$ nanoparticles as shown in Table 4 . The calculated degradation rate constant $(\mathrm{K})$ of $\mathrm{PRL}$ is $0.206 \mathrm{~d}^{-1}$ and the theoretical half-life of PRL is 3.364 days implied that the removal of PRL by yeast consortium was time dependent process and degradation rate was directly proportional to substrate concentration (Jin et al., 2017).

Table 4 Kinetic parameters for the degradation of perylene (PRL) using yeast consortium YC02

Set of conditions $\quad$ Kinetics equation of degradation Rate constants of degradation

$\mathrm{R}^{2}$ Zero order

$\mathrm{PRL}+\mathrm{YC02}$

$\mathrm{PRL}+\mathrm{YCO} 2+$ biosurfactant

$\mathrm{PRL}+\mathrm{YCO} 2+$

$\mathrm{ZnO}$ nanoparticles $\left(0.5 \mathrm{~g} \mathrm{~L}^{-1}\right)$

$\mathrm{PRL}+\mathrm{YCO} 2$ + biosurfactant

$+\mathrm{ZnO}$ nanoparticle $\left(0.5 \mathrm{~g} \mathrm{~L}^{-1}\right)$

$\mathrm{PRL}+\mathrm{YC} 02$

PRL + YCO2 + biosurfactant

$\mathrm{PRL}+\mathrm{YCO} 2+$

$\mathrm{ZnO}$ nanoparticles $\left(0.5 \mathrm{~g} \mathrm{~L}^{-1}\right)$

$\mathrm{PRL}+\mathrm{YC} 02+$ biosurfactant

$+\mathrm{ZnO}$ nanoparticle $\left(0.5 \mathrm{~g} \mathrm{~L}^{-1}\right)$

Second order

$\mathrm{PRL}+\mathrm{YCO} 2$

$\mathrm{PRL}+\mathrm{YCO} 2+$ biosurfactant

$\mathrm{PRL}+\mathrm{YCO} 2+$

$\mathrm{ZnO}$ nanoparticles $\left(0.5 \mathrm{~g} \mathrm{~L}^{-1}\right)$

PRL + YC02 + biosurfactant

$\left(0.5 \mathrm{~g} \mathrm{~L}^{-1}\right)$
$\mathrm{C}_{\mathrm{t}}=-5.520 \mathrm{t}+48.91$

$C_{t}=-5.565 t+48.77$

$C_{t}=-5.885 t+48.43$

$C_{t}=-5.960 t+48.38$
First order

$\ln C_{t}=-0.1822 t+3.9433$

$\ln C_{t}=-0.1847 t+3.9401$

$\ln C_{t}=-0.2008 t+3.9303$

$\ln C_{t}=-0.2060 t+3.9321$

$1 / \mathrm{C}_{\mathrm{t}}=0.0066 \mathrm{t}+0.0166$

$1 / \mathrm{C}_{\mathrm{t}}=0.0067 \mathrm{t}+0.0167$

$1 / \mathrm{C}_{\mathrm{t}}=0.0076 \mathrm{t}+0.0168$

$1 / C_{t}=0.0079 t+0.0166$

$\mathrm{K}\left(\mathrm{d}^{-1}\right)$

$\mathrm{T}_{1 / 2}$ (days)

$\begin{array}{lll}0.9935 & 5.520 & 4.529 \\ 0.9918 & 5.565 & 4.492 \\ 0.9735 & 5.885 & 4.428 \\ & & \\ 0.9741 & 5.960 & 4.195\end{array}$

$\begin{array}{ccc}0.9891 & 0.1822 & 3.804 \\ 0.9920 & 0.1847 & 3.752 \\ 0.9929 & 0.2008 & 3.451 \\ & & \\ 0.9938 & 0.2060 & 3.364\end{array}$

$\begin{array}{lll}0.9316 & 0.0066 & 3.030\end{array}$

$\begin{array}{lll}0.9379 & 0.0067 & 2.985\end{array}$

$\begin{array}{lll}0.9720 & 0.0076 & 2.632\end{array}$

$\begin{array}{lll}0.9697 & 0.0079 & 2.532\end{array}$
529

428

195

\section{CONCLUSION}

To conclude, anionic biosurfactant was produced by yeast consortium YC02 which could enhance the degradation of perylene (PRL) in the growth medium. However, the best improvement on PRL degradation evaluated to $70.0 \%$ which was recorded in the presence of biosurfactant and $\mathrm{ZnO}$ nanoparticles both. In addition, statistical optimization of growth parameters remarkably enhanced the PRL degradation $(74 \%)$ by $\mathrm{YCO} 2$ in presence of $\mathrm{ZnO}$ nanoparticles and produced biosurfactant which establishes the novelty of our work. Results suggested the potential applicability of the yeast consortium YC02 for the bioremediation of PRL contaminated sites using biosurfactant and specific concentration of $\mathrm{ZnO}$ nanoparticles. Kinetic studies suggested that degradation of PRL by yeast consortium was time dependent process and degradation rate was directly proportional to substrate concentration. According to the best of our knowledge, this is the first report on nanobioremediation of PRL, a high molecular weight PAH using yeast consortium. Further work on application of YC02 in nanoremediation of PRL from the real-world contaminated environment is underway in order to ascertain its relevance in pollution control.

Acknowledgement: The authors are grateful to VIT, Vellore for providing necessary laboratory facilities.

\section{REFERENCES}

Agarry, S. E., Aremu, M. O. \& Aworanti, O. A. (2013). Kinetic modelling and half-life study on enhanced soil bioremediation of bonny light crude oil amended with crop and animal-derived organic wastes. J Petrol Environ Biotech, 4, 137. https://doi. org/10.4172/2157-7463.1000137

Arulazhagan, P., Vasudevan, N. \& Yeom, I. T. (2010). Biodegradation of polycyclic aromatic hydrocarbon by a halotolerant bacterial consortium isolated from marine environment. Int J Environ Sci Tech, 7, 639-652. https://doi.org /10.1007/BF03326174

Bodour, A. A. \& Miller-Maier, R. M. (1998). Application of a modified dropcollapse technique for surfactant quantitation and screening of biosurfactantproducing microorganisms. $J$ Microbiol Meth, 32, 273-280. https://doi.org/10.1016/S0167-7012(98)00031-1

Bodour, A. A., Guerrero-Barajas, C., Jiorle, B. V., Malcomson, M. E., Paull, A. K., Somogyi, A., Trinh, L. N., Bates, R. B. \& Maier, R. M. (2004). Structure and characterization of flavolipids, a novel class of biosurfactants produced by Flavobacterium sp. strain MTN11. Appl Environ Microbiol, 10, 114-120 https://doi.org/ 10.1128/AEM.70.1.114-120.2004

Capellos, C. \& Bielski, B. H. (1972). Kinetic systems: mathematical description of chemical kinetics in solution. New York, USA:Wiley-Inter science.

Cunha A., Almeida, A., Martins, A. R. A. \& Alkantara, F. (2006). Perylene toxicity in the estuarine environment of Ria de Aveiro (Potgugal). Ecotoxicology, 15, 171-185. https://doi.org/10.1007/s 10646-005-0046-0

Donaldson, D. M., Robertson, J. M. \& White, J. G. (1953). The crystal and molecular structure of perylene. P Roy Soc Lond A Mat Phy Sci, 220, 311-321. https://doi.org/10.1098/rspa.1953.0189.

El-Sheshtawy, H. S. \& Ahmed, W. (2017). Bioremediation of crude oil by Bacillus licheniformis in the presence of different concentration nanoparticles and produced biosurfactant. Int J Environ Sci Tech, 14, 1603-1614. https://doi.org/10.1007/s13762-016-1190-1

Gan, S., Lau, E. V. \& Ng, H. K. (2009). Remediation of soils contaminated with polycyclic aromatic hydrocarbons (PAHs). J Hazard Mater, 172, 532-549. https://doi.org/10.1016/j.jhazmat. 2009.07.118

Haghighat S, Akhavan, A., Assadi, M. M. \& Pasdar, S. H. (2008). Ability of indigenous Bacillus licheniformis and Bacillus subtilis in microbial EOR. Int J Environ Sci Tech, 5, 385-390. https://doi.org/10.1007/BF03326033

Hesham, A. E. L., Khan, S., Liu, X. C., Zhang, Y., Wang, Z. \& Yang, M. (2006). Application of PCR-DGGE to analyse the yeast population dynamics in slurry 
reactors during degradation of polycyclic aromatic hydrocarbons in weathered oil. Yeast, 23, 879-887. https://doi.org/10.1002/yea.1401

Hu, L., Shi, X., Lin, T., Guo, Z., Ma, D. \& Yang, Z. (2014). Perylene in surface sediments from the estuarine-inner shelf of the East China Sea: A potential indicator to assess the sediment footprint of large river influence. Cont Shelf Res, 90, 142-150. https://doi.org/10.1016/j.csr.2014.04.014

Irwin, R. J., Van Mouwerik, M., Stevens, L., Seese, M. D. \& Basham, W. (1997). Environmental contaminants encyclopedia perylene entry, National Park Service, Water Resources Division, Fort Collins, Colorado.

Itoh, N. \& Hanari, N. (2010). Possible precursor of perylene in sediments of lake Biwa elucidated by stable carbon isotope composition. Geochem J, 44, 161-166. https://doi.org/10.2343/ geochemj.1.0054

Jin, X., Tian, W., Liu, Q., Qiao, K., Zhao, J. \& Gong, X. (2017). Biodegradation of the benzo[a]pyrene-contaminated sediment of the Jiaozhou Bay wetland using Pseudomonas sp. immobilization. Mar Pollut Bull, 117, 283-290. http://doi.org/10.1016/j.marpolbul. 2017.02.001

Kephalopoulos, S., Csobod, E., Bruinen de Bruin, Y. \& De Oliveira Fernandes, E. (2014). Guidelines for healthy environments within European schools, Copublished by the European Commission's Directorates General for Health and Consumers and Joint Research Centre, Luxembourg.

Kulkarni, S. S. \& Shirsat, M. D. (2015). Optical and structural properties of zinc oxide nanoparticles. Int $J$ Adv Res Phy Sci, 2, 14-18.

Kumar, H. \& Rani, R. (2013). Structural and optical characterization of $\mathrm{ZnO}$ nanoparticles synthesized by microemulsion route. Int Lett Chem Phys Astron 19, 26-36. https://doi.org/10.18052/www.scipress.com/ILCPA.19.26

Litt, G. \& Almquist, G. (2009). An investigation of $\mathrm{CuO} / \mathrm{Fe}_{2} \mathrm{O}_{3}$ catalysts for the gas-phase oxidation of ethanol. Appl Catal B Environ, 90, 10-17. https://doi.org/10.1016/i.apcatb.2009.02.001

Mandal, S .K. \& Das, N. (2018). Biodegradation of perylene and benzo[ghi]perylene (5-6 rings) using yeast consortium: kinetic study, enzyme analysis and degradation pathway. J Environ Biol, 39, 5-15. https://doi.org/10.22438/jeb/39/1/MRN-540

Marynowski, L., Smolarek, J. \& Hautevelle, Y. (2015). Perylene degradation during gradual onset of organic matter maturation. Int J Coal Geol, 139, 17-25. https://doi.org/10.1016/i.coal.2014.04.013

Mishra, S., Singh, S. N. \& Pande, V. (2014). Bacteria induced degradation of fluoranthene in minimal salt medium mediated by catabolic enzymes in vitro condition. Bioresource Technol, 164, 299-308. https://doi.org/10.1016/j.biortech.2014.04.076

Nezahat, B., Nebahat, D. \& Dilhan. M.K. (2009). Conversion of biomass to fuel: transesterification of vegetable oil to biodiesel using $\mathrm{KF}$ loaded nano-g- $\mathrm{Al}_{2} \mathrm{O}_{3}$ as $\begin{array}{lllll}\text { catalyst. Appl Catal B Environ, } & \text { 89, 590-596. }\end{array}$ https://doi.org/10.1016/i.apcatb.2009.01.026

Parthasarathi, V. \& Thilagavathi, G. (2011). Synthesis and characterization of zinc oxide nanoparticle and its application on fabrics for microbe resistant defence clothing. Int J Pharm Pharmaceut Sci, 3, 392-398.

Qin, W., Zhu, Y., Fan, F., Wang, Y., Liu, X., Ding, A. \& Dou, J. (2017) Biodegradation of benzo $(a)$ pyrene by Microbacterium sp. strain under denitrification: Degradation pathway and effects of limiting electron acceptors or carbon source. Biochem Eng J, 121, 131-138. https://doi.org/10.1016/i.bej.2017.02.001

Raza, Z. A., Rehman, A., Khan, M. S. \& Khalid, Z. M. (2007). Improved production of biosurfactant by a Pseudomonas aeruginosa mutant using vegetable oil refinery wastes. Biodegradation, 18, 115-121. https://doi.org/10.1007/s10532-006-9047-9

Sahoo, C. \& Gupta, A. K. (2012). Optimization of photocatalytic degradation of methyl blue using silver ion doped titanium dioxide by combination of experimental design and response surface approach. J Hazard Mater, 215, 302 310. https://doi.org/10.1016/ i.jhazmat.2012.02.072

Satpute, S. K., Bhawsar, B. D., Dhakephalkar, P. K. \& Chopade, B. A. (2008). Assessment of different screening methods for selecting biosurfactant producing marine bacteria. Indian J Geo-Mar Sci, 37, 243-250.

Shin, K. H. \& Cha, D. K. (2008). Microbial reduction of nitrate in the presence of nanoscale zero-valent iron. Chemosphere, 72, 257-262. https://doi.org/10.1016/i.chemosphere.2008.01.043

Silva, I. S., Grossman, M. \& Durrant, L. R. (2009). Degradation of polycyclic aromatic hydrocarbons (2-7 rings) under microaerobic and very-low-oxygen conditions by soil fungi. Int Biodeterior Biodegr, 63, 224-229. https://doi.org/10.1016/j.ibiod.2008.09.008

Slater, G. F., Benson, A. A., Marvin, C. H. \& Muir, D. C. (2013). PAH fluxes to Siskiwit revisted: trends in fluxes and sources of pyrogenic PAH and perylene constrained via radiocarbon analysis. Environ Sci Technol, 47, 5066-5073 https://doi.org/10.1021/es 400272z

Stefanova, M., Ivanov, D. A. \& Simoneit, B. R. T. (2013). Paleoenvironmental application of Taxodium macrofossil biomarkers from the Bobov dol coal formation, Bulgaria. Int $J$ Coal Geol, 120, 102-110. https://doi.org/10.1016/j.coal.2013.10.005

U.S. Environmental Protection Agency (US EPA). (2007). Provisional peer reviewed toxicity values for perylene (CASRN 198-55-0), Superfund health risk technical support center national center for environmental assessment, office of research and development, U.S. Environmental Protection Agency, Cincinnati, $\mathrm{OH} 45268$.

Varnosfaderany, M.N., Bakhtiari, A.R., Gu, Z. \& Chu, G. (2014). Perylene as an indicator of land-based plant biomarkers in the southwest Caspian Sea. Mar Pollut Bull, 80, 124-131. https://doi.org/10.1016/j.marpolbul.2014.01.033

Wang, J., Quan, X., Han, L., Yia, Q. \& Hegemann, W. (2002). Microbial degradation of quinolone by immobilized cells of Burkholderin pickettii [J]. Water Res, 36, 2288-2296. https://doi.org/10.1016/S0043-1354(01)00457-2

Zhang, X., Yan, S., Tyagi, R.D. \& Surampall, R. (2011). Synthesis of nanoparticles by microorganisms and their application in enhancing microbiological reaction rates. Chemosphere, 82, 489-494. https://doi.org/10.1016/j.chemosphere.2010.10.023 